Revista Complutense de Historia de América

ISSN: 1132-8312

http://dx.doi.org/10.5209/RCHA.61086

\title{
El enviado del imperio entre nosotros: la visita del secretario de Estado Philander Chase Knox a Costa Rica (1912)
}

\author{
Carlos Humberto Cascante Segura ${ }^{1}$
}

Recibido: 5 de diciembre de 2017 / Aceptado 22 de abril de 2018

Resumen. El artículo analiza los elementos contextuales y las implicaciones de la visita del secretario de Estado de los Estados Unidos Philander C. Knox a Costa Rica en 1912. El objetivo fundamental de este análisis consiste en comprender los propósitos de las autoridades costarricenses durante la estadía de Knox y su comitiva en el país: así como las percepciones reciprocas existentes tanto en Costa Rica y como en las autoridades gubernamentales de los Estados Unidos durante esos años. La evidencia existente demuestra que pese a existir en Costa Rica animadversión a la política estadounidense del momento, esta no condicionó la actuación de las elites políticas que preferían seguir una política pragmática; asimismo, la puesta en escena permitió consolidar en la visión de las autoridades estadounidenses la idea de la excepcionalidad costarricense en la región.

Palabras clave: Diplomacia del dólar; antiimperialismo; política exterior; Philander Knox; relaciones Costa Rica-Estados Unidos; Costa Rica; siglo XX.

\section{[en] The Envoy of the Empire among us: the Visit of the US Secretary of State Philander Chase Knox to Costa Rica (1912)}

\begin{abstract}
This article analyzes the contextual factors and the implications of the visit of Secretary of State of the United States Philander C. Knox, to Costa Rica in 1912. The main objective of this study is to understand the purposes of the Costa Rican authorities during the stay of Knox and his entourage in the country, as well as the reciprocal perceptions that existed both in Costa Rica and in the governmental authorities of the United States during those years. The existing evidence demonstrates that despite the existence of animosity in Costa Rica to the US policy of the moment, this did not condition the performance of the political elites that preferred to follow a pragmatic policy; likewise, the staging made it possible to consolidate the idea of the Costa Rican exceptionalism in the region in the eyes of the American authorities.

Keywords: Dollar Diplomacy; Antiimperialism; Foreign Policy; Philander Knox; Costa Rica-United States Relationship; Costa Rica; 20th Century.
\end{abstract}

Sumario. 1. Consideraciones iniciales y componentes metodológicos. 2. Un imperio en crecimiento y una frontera inestable: el contexto de la visita de Knox a Centroamérica. 3. Pompa y circunstancia en la pequeña Costa Rica. 4. Narrativas divergentes: entre el pragmatismo y el antiimperialismo. 5. Impresiones imperiales. 6. A modo de conclusión. 7. Referencias bibliográficas.

1 Estudiante del programa de Doctorado en Historia de la Universidad de Costa Rica, profesor de la Escuela de Relaciones Internacionales de la Universidad Nacional de Costa Rica y de la Escuela de Ciencias Políticas de la Universidad de Costa Rica.

E-mail: carlos.cascantesegura@ucr.ac.cr y carlos.cascante.segura@una.ac 
Cómo citar: Cascante Segura, C. (2018) El enviado del imperio entre nosotros: la visita del secretario de Estado Philander Chase Knox a Costa Rica (1912), en Revista Complutense de Historia de América 44, 211-233.

\section{Consideraciones iniciales y componentes metodológicos}

Las relaciones entre Costa Rica y los Estados Unidos han sido calificadas en diversos ámbitos como excepcionales. En efecto, a diferencia de otros países latinoamericanos y, particularmente en Centroamérica y el Caribe, donde las relaciones han estado marcadas por una intervención abierta de los Estados Unidos y la desconfianza de las sociedades que han experimentado estas acciones, Costa Rica ha mantenido una relación relativamente cordial con el "hégemon" regional ${ }^{2}$. Esa premisa ha predominado en los trabajos desarrollados tanto en la historiografía costarricense, en la que se destacan los elaborados por Murillo ${ }^{3}$, Solís ${ }^{4}$, Shifter ${ }^{5}$, Sáenz Carbonell ${ }^{6}$ y Díaz como en aquellos elaborados por la academia estadounidense, dentro de los que se destacan los de Salisbury ${ }^{8}$, Longley ${ }^{9}$ y Olander $^{10}$.

Desde esta perspectiva, el trabajo de Longley constituye un punto clave en la búsqueda por comprender las particularidades de dicha relación. En este se sostiene -a partir del uso de la teoría de las percepciones y la construcción de imágenes- que entre los líderes estadounidenses se desarrolló durante el siglo XX una imagen específica de las virtudes de la sociedad costarricense, que se contrapone con el resto de las sociedades centroamericanas, lo que ha llevado a las autoridades estadounidenses a tomar decisiones específicas diferentes a las que se han tomado en otros países y donde las crisis son excepciones que confirman la regla. Por consiguiente, esa serie de imágenes compartidas permiten que, aunque existan ciertas crisis en la relación, esta puede recomponerse y retornar a niveles de normalidad y estabilidad. Asimismo, esas percepciones han sido utilizadas y reforzadas por los líderes políticos costarricenses, dado que permitieron ampliar su margen de maniobra para lidiar con la hegemonía estadounidense ${ }^{11}$.

Esta argumentación es seguida, en parte, en un trabajo reciente de Díaz Arias, quien al analizar la visita del presidente John F. Kennedy a Costa Rica en 1963 sostiene que con este evento político se vino a reforzar las bases de esta relación entre ambos actores. Este resultado se consiguió mediante un entramado simbólico que acuerpó una serie de discursos que rescataban la excepcionalidad costarricense en el istmo centroamericano y su ligamen con los Estados Unidos, al establecerse -al

\footnotetext{
2 Un recuento histórico de las relaciones entre Estados Unidos y América Latina en Longley, 2002; O'Brien, 2007. Un estudio de largo alcance sobre las relaciones entre los Estados Unidos y Centroamérica en Coastworth, 1994.

Murillo Jiménez, 1981.

Solís Rivera, 1990.

Schifter Sikora, 1986.

Sáenz Carbonell, 1996 y 2000.

Díaz Arias, 2017.

Salisbury, 1982 y 1984.

Longley, 1997.

Olander, 1996.

Longley, 1997: 1-19.
} 
menos discursivamente- que ambas sociedades compartían visiones similares en su desarrollo, lo cual había sido aceptado por la mayoría de la población costarricense ${ }^{12}$.

Este artículo pretende retrotraer más esa búsqueda e indagar las percepciones existentes sobre las relaciones entre Costa Rica y los Estados Unidos en algunos sectores de ambos países a principios del siglo XX. Por tal motivo, se estudian las reacciones de ambas partes relativas a la visita del secretario de Estado Philander Chase Knox a Costa Rica, en el marco de su gira de "buena voluntad" por los países de Centroamérica y el Caribe. Para este propósito se cuenta con dos tipos de fuentes. El primero se compone de los discursos oficiales emitidos durante toda la gira (tanto los producidos por el gobierno de los Estados Unidos por los gobiernos de la región) y la correspondencia oficial producida por las autoridades estadounidenses y costarricenses; que permite acercarse a la visión que los funcionarios de ambos países desarrollaron antes, durante y después de la estancia de Knox en Costa Rica. El segundo consiste en una base de datos de las publicaciones de prensa producidas en Costa Rica entre el 28 de febrero de 1912 y el 5 de marzo de 1912. Este corpus documental, compuesto por 53 unidades, ha sido sometido al análisis de contenido cualitativo $^{13}$, el cual permite la identificación categorías en los textos periodísticos que se produjeron durante ese periodo.

La información recabada se encuentra organizada en cuatro secciones para su análisis. La primera establece el contexto general de la visita dentro del proceso de control estadounidense de la cuenca del Caribe y los conflictos internos de Centroamérica, que se entrelazan en el periodo comprendido entre 1898 y 1917. La segunda parte describe las características y particularidades de la visita oficial, así como los elementos simbólico-ceremoniales que esta revistió. El tercero, analiza el contenido de los discursos que en la prensa costarricense provocó la llegada de Knox, en este caso se utiliza la prensa como un indicador de la diversidad de percepciones existentes en el Costa Rica sobre la política exterior estadounidense. Por último, el cuarto apartado se cuestiona los efectos de la visita en las percepciones de los funcionarios estadounidenses, a partir de sus discursos públicos y la correspondencia interna que se produjo durante esas fechas.

\section{Un imperio en crecimiento y una frontera inestable: el contexto de la visita de Knox a Centroamérica}

Durante periodo comprendido entre 1898 y 1917 los Estados Unidos consolidaron su posición hegemónica en Centroamérica. Un mayor grado de interdependencia económica y política condujo a que, impulsados por la visión geopolítica de Alfred T. Mahan, los políticos estadounidenses realizarán una serie de intervenciones constantes (directas o indirectas) sobre los países centroamericanos y caribeños con el fin de asegurarse su espacio marino y la indispensable ruta interoceánica. Por ende, Centroamérica y las islas del Caribe se tornaron en una zona bajo la hegemonía estadounidense, que debía ser protegida tanto de amenazas externas como de amenazas internas ${ }^{14}$. Es así como conceptualizaciones dentro de la política exterior

\footnotetext{
Díaz Arias, 2017: 202-203.

Sobre los métodos de análisis de contenido cualitativo ver: Mayring, 2014; Schreier, 2012.

Grandin, 2006: 30-33.
} 
estadounidense como el "Corolario Roosevelt", la política del "Gran Garrote" y la "Diplomacia del Dólar" justificaron intervenciones armadas y económicas, dentro de las cuales se encuentran, entre otras, incursiones en Cuba (1898-1902 y 1906-1909), Puerto Rico (1898), Nicaragua (1894, 1899, 1909, 1912-1925), Colombia (1901, 1902, 1903), Panamá (1904), Venezuela (1903), Santo Domingo (1903) y Honduras $(1907,1911)^{15}$. La expansión de las actividades diplomáticas y militares estadounidenses estuvo precedida por un aumento sostenido de la inversión privada, la que fue desarrollada por hombres de negocios, que vieron en los países centroamericanos la oportunidad de aumentar sus fortunas, en muchos casos explotando la debilidad e inestabilidad de sus gobiernos, mediante contratos abusivos que garantizaban el control de bastos territorios, el dominio de los medios de transporte y los puertos, entre otros componentes importantes de los sistemas económicos ${ }^{16}$.

La política expansionista estadounidense de esas décadas llevó a la consolidación de los sentimientos antiimperialistas y antiamericanistas en grupos de políticos e intelectuales en los países centroamericanos y caribeños ${ }^{17}$. Esta realidad no resultaba ajena a los políticos estadounidenses, quienes pretendían por diversos medios galvanizar dichos levantamientos. Dentro de esos intentos se encontraron, por ejemplo, la visita a Sudamérica y el Caribe del secretario de Estado Elihu Root en 1906 (durante la cual participó en la III Conferencia Panamericana) ${ }^{18}$, o bien, el establecimiento de soluciones arbitrales a los conflictos en Centroamérica, como por ejemplo los tratados de Washington de $1907^{19}$. No obstante, tanto el Panamericanismo como las intervenciones de mediación de esos años chocaron con las necesidades del crecimiento imperial, por lo que fueron inútiles para detener el crecimiento de los movimientos antiimperialistas en la región.

Al asumir la presidencia de los Estados Unidos en 1909, William Howard Taft propuso reducir la influencia del "Corolario Roosevelt" y mejorar las relaciones con los países latinoamericanos. Asimismo, el nuevo secretario de Estado, Philander Chase Knox, quien se encontraba fuertemente ligado a los círculos financieros estadounidenses, propuso un cambio del "Gran Garrote" por el incremento de la financiación de los gobiernos latinoamericanos ${ }^{20}$. Con este fin fue elaborada la denominada "Diplomacia del Dólar", esta doctrina que proponía que banqueros estadounidenses asumieran las deudas que los gobiernos latinoamericanos habían adquirido con acreedores europeos, lo que les permitiría evitar intervenciones europeas en su zona de influencia. Estos acuerdos serían patrocinados por el gobierno estadounidense, que mediante convenios internacionales se asegurarían de efectuar "una supervisión benevolente" del comportamiento económico de sus deudores, para de esa forma garantizar el encuentro de la paz, la civilización y la estabilidad en esos "rotten little countries" 21 . Esta iniciativa se encontraba basada en tres presunciones:

15 McPherson, 2016: 55-71. La visión de control comercial de América Latina había iniciado un par de décadas atrás con el Panamericanismo estadounidense que se presentaba como un mecanismo de expansión comercial para competir y desplazar la enorme influencia comercial europea en América Latina. Maya Sotomayor, 1996: 776

16 Quesada Monge, 2013.

17 Sobre un análisis del origen antiimperialismo y el antiamericanismo en América ver: Inacua Gómez, 2016; para el caso centroamericano ver Lindo-Fuentes, 2015 y el costarricense Cuevas Molina, 2008: 39.

18 Sobre la gira de Root ver Rodríguez Díaz, 2004.

19 Sobre la Corte de Justicia ver Dodd, 1986.

20 Longley, 2002: 81-163.

21 Herring, 2008: 1943-1944. 
la falta de educación existente en las sociedades que debían ser auxiliadas, la falta de poblaciones blancas y la falta de una clase media de emprendedores, de forma que conservaba intacta la misma percepción de superioridad racial que había alimentado el expansionismo de años anteriores ${ }^{22}$.

De acuerdo con Herring, los intentos por establecer la "Diplomacia del Dólar" provocaron "unos pocos acuerdos, poca estabilidad y numerosas intervenciones militares" ${ }^{23}$. Adicionalmente, el apoyo a los hombres de negocios generó un aumento constante de la inversión estadounidense en Centroamérica y, prácticamente, ligó su política exterior con los intereses económicos de los financistas. Precisamente, poco tiempo después de iniciar la administración Taft se produjeron fuertes intervenciones en Nicaragua y Honduras, estas provocaron la dimisión del presidente de Nicaragua, José Santos Zelaya, obligado por la amenaza del propio secretario de Estado (la denominada nota Knox), y la instauración de un ambicioso programa de préstamos y la presencia de consejeros financieros en ambos países ${ }^{24}$. Asimismo, durante toda su gestión, Knox trató de negociar un acuerdo financiero entre banqueros estadounidenses y el gobierno de Guatemala para regular las finanzas de este país que finalmente no tuvo éxito ${ }^{25}$. Dicho ejercicio hegemónico volvió a provocar una fuerte reacción de los antiimperialistas centroamericanos quienes se identificaron especialmente con las causas hondureña y nicaragüense ${ }^{26}$.

En este contexto, la visita del secretario de Estado Knox se planeó como una gira de buena voluntad, dirigida a apoyar la política de arreglos financieros, legitimar sus acciones en la región y apaciguar los ánimos de las elites políticas centroamericanas y caribeñas. En esta línea, el entonces subsecretario de Estado, Huntington Wilson, señalaba que la gira en cuestión abriría una nueva era de las relaciones con los países que rodeaban el Mar Caribe a pocos meses de la apertura del Canal de Panamá27. Similar percepción (o esperanza) se tenía desde algunas revistas de importancia en los Estados Unidos, así en el editorial de la revista de la "American Internacional Society" se indicaba que la gira serviría para llamar la atención de los gobiernos visitados sobre las ventajas de la nueva ruta interoceánica, el comercio y la inversión estadounidense en la zona ${ }^{28}$.

Así, Knox junto con su esposa y demás miembros de su comitiva zarparon de Key West, Florida, el 23 de febrero en un periplo que se extendió hasta el 17 de abril. En este visitarían en una primera etapa Panamá, Costa Rica, Nicaragua, Honduras, El Salvador, Guatemala; en una segunda etapa Venezuela, Santo Domingo (República Dominicana), Puerto Rico, Haití, Cuba, Jamaica y algunas Antillas menores ${ }^{29}$.

\footnotetext{
Rosemberg, 1999: 64.

Herring, 2008: 1944.

Un recuento sucinto de estos hechos que provocaron la dimisión del presidente nicaragüense José Santos Zelaya en Longley, 2002: 133-135. Un análisis profundo de las intervenciones estadounidenses en Nicaragua en Gobat, 2005: $73-121$.

25 Dinwoodie, 1970: 237-253.

26 Por ejemplo, ver Merlos, 1914: 155-202.

27 Telegrama dirigido al encargado de Negocios en Centroamérica por el subsecretario de Estado de los Estados Unidos, Huntington Wilson. 24-II-1912. U.S. Department of State, 1919. Disponible en http://digital.library. wisc.edu/1711.dl/FRUS.FRUS1912

28 Editorial Comment, 1912: 493-498 y 493.

29 U.S. Department of State, 1913: VI.
} 


\section{Pompa y circunstancia en la pequeña Costa Rica}

Durante las primeras décadas del siglo XX Costa Rica experimentó una transformación política y social acelerada. En el campo político, luego de dos experiencias autoritarias al cerrar el siglo XIX, se había impuesto una reforma democrática, que daba paso a la competencia electoral (en muchos casos fraudulenta), que incorporó con mayor fuerza a las clases subalternas. Asimismo, desde la década de 1880 el Estado había aumentado sistemáticamente el gasto en salud, educación y obras públicas, lo que le permitía un relativo manejo de la conflictividad social. Este proceso estuvo concatenado con un cambio paulatino de la orientación de la economía, predominantemente agroexportadora, que desde la década de 1880 se dirigía en mayor grado al mercado estadounidense, especialmente, por la presencia cada vez más evidente de inversionistas de ese país en el banano, los ferrocarriles y la producción de electricidad ${ }^{30}$.

La inversión social produjo, a su vez, una nueva generación de intelectuales que ya para la primera década del siglo XX mantuvo una línea crítica sobre las ideas políticas liberales decimonónicas dominantes en el país. Este cuestionamiento abarcó desde su visión económica, las diferencias de clase ("la cuestión social"), así como la relación con las grandes potencias. En este sentido, las reiteradas intervenciones estadounidenses en la región y, en especial, el aumento de las inversiones estadounidenses en Costa Rica (mayoritariamente de la United Fruit Company y la Northem Railway Co.) provocaron que este grupo desarrollase un férreo discurso antiimperialista. Estos intelectuales se organizaron en diversos periódicos y revistas, por lo que podían establecer un mecanismo apropiado para la difusión de sus ideas que logró tener algún éxito dentro de la elite política costarricense ${ }^{31}$. Cabe señalar que pocos años antes de la visita, la discusión y aprobación de los contratos con la United Fruit Company (1907) y la Northem Railway Co. (1908) permitieron un escenario propicio para el desarrollo de este tipo de discursos en los medios de prensa controlados por los intelectuales antiimperialistas.

Junto con el desarrollo interno, se elaboró y ejecutó una modesta política exterior en la que la incorporación al sistema comercial internacional, la definición de los límites territoriales y la creación de una imagen internacional constituían los objetivos fundamentales. En la medida que los Estados Unidos aumentó su peso político y económico en las relaciones exteriores centroamericanas, el vínculo con la potencia del norte se tornó cada vez más trascendental para conseguir dichos propósitos ${ }^{32}$. En ese contexto, el gobierno organizó la visita de tal manera que Knox y su comitiva

30 En esta línea, destaca en Costa Rica la figura de Minor Cooper Keith, quien aprovechó las condiciones acuciantes de la deuda externa del país para desarrollar la compañía de ferrocarriles. Asimismo, producto de ese negocio adquirió las tierras necesarias para la producción de banano, que le permitió fundar con otros socios la United Fruit Company (1899). No obstante, la actividad empresarial de Cooper Keith no se detuvo ahí, sino que realizó inversiones en minería, electricidad y otros campos de producción en Costa Rica y Centroamérica. Keith casó con Cristina Castro Fernández, hija del dos veces presidente de Costa Rica José María Castro Madriz. Este matrimonio reflejaba la influencia que dicho personaje tuvo sobre la política interna costarricense de finales del siglo XIX y principios del siglo XX. Ver Quesada Monge, 2013.

31 Molina Jiménez - Palmer, 2007: 77-98; Fumero Vargas, 2005: 2-6. Una descripción amplia de esta generación de intelectuales en Morales, 1992: 163-171. Entre los miembros más destacados de este grupo cabe mencionar a Elías Jiménez Rojas, Alejandro Alvarado Quirós, Roberto Brenes Mesén, Fabio Baudrit, José María Zeledón, Rogelio Fernández Güell, Omar Dengo, Joaquín García Monge, Carmen Lyra, Vicente Sáenz y Mario Sancho.

32 Cascante Segura, 2015: 2-13. 
pudiesen ver los avances de un país pequeño, en comparación con una región rodeada por vecinos conflictivos ${ }^{33}$. Desde esta perspectiva, las autoridades costarricenses se comportaron pragmáticamente, dado que varios de los miembros del gobierno habían mantenido algunas diferencias con las acciones del gobierno y empresarios estadounidenses en la región y el país. Incluso años atrás el propio presidente Jiménez Oreamuno, en ese entonces como diputado al Congreso, había alcanzado fama como "antiimperialista" al oponerse a los contratos con la United Fruit Company y la Northem Railway Co.; así como al sistema de tratados de Washington de 1907, al punto de calificar a esta última negociación como el primer paso para la creación de un protectorado estadounidense en la regional ${ }^{34}$.

En esta línea pragmática, el ministro de Costa Rica en Washington al negociar la preparación de la visita recomendó que Knox arribase por el Caribe, pero que su salida se diera por el Pacífico, de forma que pudiera tomar una noción de regiones importantes del país ${ }^{35}$. Es decir, el ilustre visitante debía llevarse la impresión de un país que vivía en paz y con las virtudes propias de la laboriosidad y de la pureza racial, conceptos que se habían ido desarrollando en el proceso de construcción de la identidad nacional desde mediados del siglo XIX y que, de acuerdo con esta elaboración identitaria, convertían a Costa Rica en una excepción en la región ${ }^{36}$. Para tal fin, se preparó una agenda que agasajaba al secretario de Estado y lo ponía en contacto con aquellos elementos de la realidad nacional que mejor expresaban los progresos políticos, sociales y morales, dentro de los que se encontraban los avances en medicina y las muestras de arquitectura europea construidos en la capital durante las últimas décadas del siglo XIX y los primeros años del XX.

Knox arribó al Puerto de Limón el viernes $1^{\circ}$ de marzo por la mañana. En esa ciudad fue recibido por una comitiva del gobierno integrada por el secretario de Hacienda y Comercio, Felipe Alvarado Echandi; el subsecretario de Relaciones Exteriores, Roberto Brenes Mesén; el secretario personal del presidente Jiménez, Joaquín Fernández Montufar; así como miembros distinguidos de la política costarricense de la época ${ }^{37}$. El secretario Knox fue recibido por la población local, sin que se registrase ningún incidente, y tras el desfile con las autoridades costarricenses fue llevado al Club Atlántida, donde fue recibido por el gobernador de Limón con un brindis. El gobernador de la ciudad utilizó el momento para dejar clara la particularidad costarricense al señalar que durante su viaje Knox y su comitiva podrían admirar en el país "los esfuerzos de estos [sus habitantes] y de su Gobierno han hecho, encaminándolo por la senda del Progreso en lo material, social y moral; y en lo político, en la práctica de las instituciones libres"38.

Una vez finalizada esta ceremonia, Knox se trasladó a San José en un tren de cuatro carros especialmente engalanado para la ocasión con orquídeas y otras flores

\footnotetext{
Gobierno de la República de Costa Rica, 1912.

Molina Jiménez, 2008: 28-29.

Carta J.B. Calvo, ministro de Costa Rica en Washington a Manuel Castro Quesada, secretario de Relaciones Exteriores de Costa Rica. 12-II-1912. Archivos Nacionales de Costa Rica [en adelante ANCR], Fondo Relaciones Exteriores [en adelante RREE].21917.

36 Molina Jiménez - Palmer, 1992: 169-205; Acuña Ortega, 2002; Soto-Quirós, 2013 y 2012.

37 Comisión Especial que irá a Limón a recibir al secretario Knox. La Información, 28-II-1912, n $1253,3$.

38 Mr. Knox en San José. Recibimiento que se le ha hecho al ilustre visitante. La Información, 2-III-1912, n 1276, 2.
} 
costarricenses $^{39}$. El secretario de Estado arribó en la tarde de ese día a San José, donde fue recibido por una nueva comitiva compuesta por los altos mandos del gobierno. Realizados los saludos protocolarios, Knox fue paseado en desfile oficial por las calles de San José en el carruaje presidencial en una caravana compuesta por ocho carruajes ${ }^{40}$, que llevaron a los invitados a la casa del secretario Alvarado, uno de los hombres más adinerados de Costa Rica y que contaba con una de las mejores residencias del país. Según los diarios de la época, la mansión fue adornada para la ocasión con gallardetes y arreglos florales; además, se habían reservado dos salones para el servicio de Knox y su esposa ${ }^{41}$. El desfile destacaba la relevancia de la visita, además, permitía mostrar tanto a los visitantes como el grado de progreso social y desarrollo alcanzado por la república.

Aunque no se programó un acto oficial en el resto del día, a las 8:00 pm se efectuó un concierto en honor a los huéspedes y, como estaba programado, Knox recorrió por la mañana del día siguiente la ciudad de San José. El periplo comprendió varias dependencias del Estado, entre ellas la Penitenciaría Central (construida siguiendo el pensamiento carcelario de la época), el Asilo Chapui (un hospital para enfermos mentales, considerado para ese momento como el único de su tipo en Centroamérica) y el Hospital San Juan de Dios (que también era considerado un modelo para su época) ${ }^{42}$. Estas breves visitas pretendían demostrar al diplomático los avances sociales en Costa Rica y, por ende, una diferencia adicional con el resto de los países que visitaría.

Al mediodía, Knox fue recibido oficialmente en el Palacio Nacional por el presidente Ricardo Jiménez Oreamuno y todo el gabinete, momento en que tuvieron una reunión privada. Ese mismo día la colonia estadounidense en Costa Rica le ofreció una recepción en el "Golf Club" de San José, a las 3:30 de la tarde ${ }^{43}$. Estos encuentros prepararon los actos culminantes de la gira de Knox en el país: el baile que se realizaría la noche del 2 de marzo y el banquete nocturno del día siguiente, ambos se escenificarían en el Teatro Nacional ${ }^{44}$. El "Nacional" representaba una de las grandes obras de la modernidad costarricense, pues se había construido siguiendo los lineamientos arquitectónicos de los grandes teatros de ópera europeos; su construcción pretendió desarrollar y justificar en las élites sociales su cercanía con las grandes potencias del momento, además, la edificación había sido dotada de una serie de simbolismos inspirados en los mitos de la identidad nacional costarricense.

En el caso específico de la visita su utilización pretendía demostrar al secretario de Estado la noción de un país cercano a los valores de civilización y progreso. Para ambas ocasiones el Teatro fue decorado con flores y las banderas de ambos países, asimismo se levantó una plataforma especial para orquesta y las butacas que rodeaban el escenario y la zona de luneta fueron decoradas con arreglos florales ${ }^{45}$. Adicionalmente, para el banquete de 150 comensales el gobierno contrató un chef europeo, seis mayordomos y una gran cantidad de camareros, al punto de que el encargado

39 Última hora. Despacho de nuestro enviado oficial a Limón. La Información, 1-III-1912, n 1275, 8. E1 ministro Knox en tierra costarricense. El noticiero, 2-III-1912, n $2911,2$.

40 Ibídem.

41 La residencia del secretario Knox. La República, 1-III-1912, n 8415, 1.

42 La visita del Sr. Knox á la Penitenciaria, Hospital y Asilo Chapui. El Republicano, 3-III-2012, n 42, 4.

43 La colonia americana obsequiará un te-champaña á Mr. Knox. La República, 1-III-1912, n 8415,1.

44 Baile en el Nacional. El Noticiero de la Mañana, 29-II-1912, n 2908, 2.

$45 \quad$ El baile del Nacional en honor de Mr. Knox. El Republicano, 2-III-1912, n 41, 3. 
de preparar el banquete indicó previo a este en la prensa nacional que "[s]erá una cosa soberbia, regia, cosa nunca vista en Centro América y al gobierno actual tocará la gloria de haber hecho una cosa tan grande, como las que hacía Lúpulo; será una comida igual en su grandeza y ostentación a las que daban los patricios romanos" ${ }^{\text {"46. }}$.

Dentro del banquete el presidente Jiménez Oreamuno pronunció un discurso como brindis en honor de los Estados Unidos y el secretario Knox. En este el jefe de Estado costarricense realizaba una interpretación no imperialista de la Doctrina Monroe, a la que conceptualizó como un hecho fundamental que garantizó la independencia centroamericana; además, a lo largo del discurso reiteró el vínculo entre el progreso costarricense y las instituciones estadounidenses como una relación no solo de admiración, sino de seguimiento, de tal manera señaló que:

hay otro beneficio que debemos a vuestra patria, el mayor de todos, aquel sin el cual los anteriores serían mera escoria: vaciamos nuestras instituciones en la matriz en que se fundieron las vuestras. $\mathrm{Al}$ iniciarnos en la práctica del gobierno propio,-el único que merece el decoroso reconocimiento de los hombres-, aprendimos á deletrear en vuestro famoso documento de Declaración de Independencia $[\ldots]^{47}$.

El presidente Jiménez recalcó la importancia del "gobierno propio" y como este había sido alcanzado por una pequeña nación, que aspiraba a seguir los pasos de las instituciones republicanas de los Estados Unidos. Por consiguiente, la relación entre ambos países iba más allá de la admiración de la población costarricense por la estadounidense, sino valores compartidos y enseñanzas aprendidas. Resultaba claro que el protocolo, los recorridos y el discurso pretendían fortalecer la noción de paridad civilizatoria entre estadounidenses y costarricenses. De tal forma, que la argumentación propuesta se consolidaba ligando las imágenes expuestas a lo largo del día a Knox con la historia estadounidense de la siguiente manera:

Espero, señor, que el conocimiento personal de nuestras instituciones y costumbres habrá de produciros un sentimiento de legítimo orgullo y placidez al ver fructificado en este pequeño rincón de América muchas de las semillas de buen gobierno arrebatadas á vuestros campos de libertad, por los vientos que llevan la civilización de pueblo á pueblo, y dejados caer por ellos, aquí y allá, por todos los ámbitos de la tierra ${ }^{48}$.

Finalmente, el discurso de Jiménez recalaba en los inversionistas estadounidenses en Costa Rica, a los que no dudo en calificar como un bastión de la economía costarricense y como un ejemplo más del buen estado de las relaciones entre ambos países, al tiempo que subrayaba el respeto a los derechos de propiedad de estas empresas, pues "[1]ejos de fruncir el ceño ante su buena suerte, estamos contento

\footnotetext{
46 Lo que comerá Mr. Knox. La Información, 28-II-1912, nº 1273, 6.

47 Discurso del presidente de Costa Rica, Ricardo Jiménez Oreamuno, con motivo del banquete de honor al secretario de Estado Philander C. Knox. La Información, 5-III-1912, n 1278, 2.

48 Ibídem: 2.
} 
de verlos; sus ganancias no se derivan de favores legislativos, su prosperidad no disminuye, por el contrario, aumenta vigorosamente la prosperidad de la nación"49.

Cabe recalcar, adicionalmente, que en el transcurso de los dos días que Knox estuvo en San José recibió visitas de lo más granado de la élite política costarricense (por ejemplo, el futuro presidente Cleto González Víquez) y de la colonia estadounidense (por ejemplo, Minor Cooper Keith, a quien se hizo referencia anteriormente). Esto permitía demostrar que más allá de las voces críticas existentes en la sociedad costarricense, las elite políticas y económicas valoraban positivamente la relación con los Estados Unidos.

Con el protocolo del caso, la visita concluyó el 4 de marzo, cuando Knox se trasladó al puerto de Puntarenas, acompañado por el secretario de Relaciones Exteriores, para luego de una breve ceremonia en un club de la localidad abordar el buque insignia que lo llevaría a la próxima escala de su viaje: el puerto de Corinto en Nicaragua ${ }^{50}$.

El gobierno costarricense siguió utilizando la gira de Knox para posicionar su imagen en los Estados Unidos. Pocos días después de esta, la Legación costarricense en Washington mandó a publicar un pequeño folleto, que incluía una traducción del discurso del presidente Jiménez de su discurso del banquete del 3 de marzo, junto con la respuesta del secretario de Estado $\mathrm{Knox}^{51}$. El documento contenía una traducción del editorial del diario oficial, La Gaceta, del 5 de marzo, con lo que se insistía, esta vez a funcionarios y principales periódicos en los Estados Unidos, sobre la cordial recepción de que fue objeto la delegación encabezada por el secretario de Estado, tanto por el gobierno como por el pueblo costarricense, un reflejo -señalaba el corto documento-de las cordiales relaciones entre "la más grande y la más pequeña de las repúblicas de América" ${ }^{52}$.

\section{Narrativas divergentes: desde el pragmatismo al antiimperialismo}

La presencia de Knox en Costa Rica generó una amplia producción periodística que permite un acercamiento a algunas de las percepciones que existían en la sociedad costarricense de principios de siglo sobre los Estados Unidos y su política exterior. En este sentido, la evidencia demuestra que existían visiones y discursos contrapuestos, sin que exista claridad para definir cuáles eran los predominantes. Estos discursos se encontraban entre dos extremos: uno de carácter pragmático que apreciaba con simpatía moderada la visita de Knox; el otro, un discurso antiimperialista y antiamericanista que criticaba agriamente la presencia de Knox en Centroamérica y Costa Rica.

La difusión de estos discursos por la prensa fue abundante. De acuerdo con el recuento realizado, que puede apreciarse en la Tabla 1, entre el 28 de febrero y el 5 de marzo se produjeron 53 notas de prensa, en ocho periódicos consultados (incluyendo a aquellos que no publicaban diariamente), para un promedio de 8.83 noticias por día

49 Ibídem.

50 Nota oficial. El Republicano: Diario de la Mañana, 28-II-1912, n 38, 1. Comité encargado de la recepción que dará la colonia americana al secretario Knox. La Información, 28-II-1912, n 1273, 5.

51 Carta J.B. Calvo, ministro de Costa Rica en Washington a Manuel Castro Quesada, secretario de Relaciones Exteriores de Costa Rica. 5-III-1912. ANCR, RREE.21917.

52 Legación de Costa Rica en Washington D.C., 1912: 1. 
(los domingos no había edición). De las 53 notas de prensa estudiadas 37 contenían juicios de valor sobre la visita (67,9 por ciento). Los medios analizados tendieron a tomar partido respecto de los discursos políticos enfrentados en la visita, así de los tres diarios con más publicaciones La Información asumió una línea crítica de la visita (que no implicó la ausencia de algunos comentarios positivos), mientras que El Republicano y en menor medida El Noticiero se inclinaron por una postura positiva. Por otra parte, de los medios de prensa con menor cantidad publicaciones todos, salvo por La República, se decantaron un discurso crítico con tintes antiimperialistas. En el caso de La Información y La Hoja Obrera esta línea de trabajo se había mantenido durante la década anterior, pues habían sido espacios utilizados por los intelectuales antiimperialistas nacionales ${ }^{53}$; sin embargo, con respecto a las otras publicaciones no existen estudios que profundicen sobre las conexiones políticas e ideológicas que los llevaron a tener una determinada línea en relación con la visita de Knox.

Tabla. 1. Distribución de noticias referentes a la visita del secretario de Estado Philander Knox por periódico y tendencia discursiva (28 de febrero a 5 de marzo de 1912) ${ }^{54}$.

\begin{tabular}{|c|c|c|c|c|}
\hline \multirow[b]{2}{*}{ Nombre del periódico } & \multicolumn{3}{|c|}{ Tendencia de la nota } & \multirow[b]{2}{*}{ Total } \\
\hline & Neutral $^{55}$ & Positiva $^{56}$ & $\begin{array}{c}\text { Elementos }^{57} \\
\text { antiimperialistas/ } \\
\text { antiamericanista }\end{array}$ & \\
\hline La Información & 7 & 4 & 7 & 18 \\
\hline El Noticiero: diario de la mañana & 4 & 4 & 2 & 10 \\
\hline El Republicano: diario de la mañana & 2 & 7 & 1 & 10 \\
\hline La Época: diario católico independiente de la tarde & 1 & & 4 & 5 \\
\hline La República & 1 & 2 & 1 & 4 \\
\hline El Pacífico: semidiario de intereses generales & 2 & & 1 & 3 \\
\hline La Hoja Obrera & & & 2 & 2 \\
\hline La Opinión: semanario independiente & & 1 & & 1 \\
\hline Total & 17 & 18 & 18 & 53 \\
\hline
\end{tabular}

¿Cuáles eran los componentes de los discursos inmersos en la prensa? Del análisis de contenido de las notas de prensa pueden determinarse tres elementos fundamentales: (a) las valoraciones sobre la política de los Estados Unidos y a la personalidad de Knox; (b) las actitudes tomadas por la población frente a la visita; así como (c) las conclusiones tras la visita de Knox.

53 Morales, 1992: 120.

54 Fuente: Elaboración propia a partir de base de datos de noticias sobre la visita de Philander C. Knox en la prensa costarricense.

55 Neutral: la nota de prensa no emite juicios de valor sobre la visita.

56 Positiva: la noticia contiene juicios positivos de valor sobre la visita, los Estados Unidos y la personalidad de Knox (utiliza adjetivos elogiosos vinculados con el personaje o el país).

57 Elementos antiimperialistas: la noticia contiene juicios de valor negativos sobre la visita, los Estados Unidos y la personalidad de Knox (utiliza adjetivos peyorativos o descalificaciones vinculados con el personaje o el país). 
Las valoraciones sobre la política exterior de los Estados Unidos y Knox tuvieron especial relevancia tanto en el día previo como en el día de arribo del secretario de Estado. Como se expondrá a continuación, la narrativa que consideraba positivamente la visita planteaba que esta constituía una oportunidad de demostrar de primera mano al visitante la excepcionalidad costarricense, estas diferencias protegerían al país de las intervenciones estadounidenses, lo que constituía una especie de reafirmación de la identidad nacional costarricense y un respaldo a una la política exterior pragmática en relación con los Estados Unidos. Por el contrario, la lectura antiimperialista de la visita consideraba que esta constituía una grave amenaza, comparable con la invasión filibustera de 1856. De tal forma, se generó a lo largo de la coyuntura analizada una disputa dialéctica, en la cual ambas partes pretendían demostrar que su posicionamiento se encontraba más cercano a la mayoría de la población.

En la línea de discursos pragmáticos, el 29 de febrero, El Republicano describía la llegada de Knox como un hecho histórico para el país, además, se realizaba una elogiosa caracterización de Knox como "uno de los exponentes más completos de la alta cultura norteamericana y de los ideales de hoy de aquella gran nación [...]". Desde esta perspectiva, la visita era el momento oportuno para demostrar la excepcionalidad costarricense, de forma que urgía "recibir al visitante de acuerdo con la cultura nacional", dado que "precisa que el nombre de Costa Rica en esa ocasión quede bien puesto". Nuevamente el artículo en cuestión realzaba la necesidad de distinguir a la "nacionalidad costarricense" de los países latinoamericanos y concluía señalando que:

Tan pequeña esta nacionalidad, tan desprestigiados los países-latinoamericanos por sus revueltas, por el irrespeto á la ley por parte de gobernados y gobernantes, por su indolencia y por mil defectos más, ella, esta pequeña nacionalidad ha sido confundida en esa mala fama ${ }^{58}$.

En la misma línea argumental, el $1^{\circ}$ de marzo La República dedicó una buena parte de la edición a resaltar la importancia de la visita, con la publicación de una foto de Knox y su esposa; así como un reportaje de una página dedicado a las funciones y relevancia del Departamento de Estado en el sistema político de los Estados Unidos. Asimismo, en una nota editorial, emitida en el semanario La Opinión, el redactor minimizaba la importancia de las voces antiimperialistas en el país, y reiteraba las razones por las cuáles Costa Rica no debía temer a "la gran nación del norte". Estas eran la identidad de sus pueblos dado que esta era la "cima de hermanos todos trabajadores, todos emprendedores, todos activos"; la ausencia de dictaduras a diferencia de los otros países del istmo y la senda de progreso que consideraba el destino costarricense. Concluía, por consiguiente, con un llamado a recibir y esperar lo mejor de la visita de Knox, pues del secretario de Estado debía "esperarse mucho bien para la Suiza de Centro América"59.

En esas mismas fechas, La Información a partir de una posición compuesta por elementos antiimperialistas esbozaría un discurso opuesto. De tal manera, publicó en su primera página una traducción de un artículo del periódico The Times Democrat

Sr. Philander C. Knox. El Republicano: Diario de la mañana, 29-II-1912, n 39, 2.

Nota Editorial. Semanario La Opinión, 3-III-1912, n 4, 2. 
de Nueva Orleans, este criticaba abiertamente a Knox y la "Diplomacia del Dólar" aplicada en Honduras ${ }^{60}$. En esa misma edición reproducía una traducción de otro artículo del mismo periódico estadounidense, en este se cuestionaba la utilidad de la visita a pocos meses del cambio de gobierno y se establecían críticas a la política de la administración Taft para el istmo. Se concluía, por consiguiente, que el éxito de la gira dependería de la capacidad de Knox para disculparse por sus errores y emprender un cambio radical de las acciones emprendidas. La edición también empleaba los preparativos de la llegada de Knox a Nicaragua para plantear su posición sobre la visita, dado que en esta nota se cuestionaba que el pueblo nicaragüense hiciera un recibimiento afectuoso a Knox, dados los hechos acaecidos en ese país en los años anteriores $^{61}$.

En esa misma edición, se reproducía un poema que circulaba por la capital, cuyo autor fue José María Zeledón (uno de los más reconocidos antiimperialistas costarricenses) y se intitulaba "Welcome! A Knox" [sic]. Esta composición comparaba la visita del secretario de Estado con la incursión del filibustero William Walker a mediados del siglo XIX, dicha relación simbólica fue empleada por los antiimperialistas costarricenses durante las primeras décadas del siglo XX como un instrumento retórico que permitía posicionar su lucha contra el crecimiento de la influencia de las compañías norteamericanas en el país durante ese periodo ${ }^{62}$. Con esta misma intención, el texto del poema criticaba la actitud pasiva y lisonjera del gobierno ante la visita del jefe de la diplomacia estadounidense y llamaba a defender a la raza "hispanoamericana" de las nuevas formas de invasión que se aproximaban al país. En uno de sus pasajes más agresivos se hacía una feroz crítica de la "Diplomacia del Dólar" y de Knox al señalar que:

Prodigando el narcótico de tu DÓLAR sonante // -que en DOLOR se convierte- cazador trashumante // de castrados leopardos, llegas á nuestros lares //con tu GRUESO GARROTE cubierto de azahares// y tu puño de hierro bajo sedeño guante.

Linchador de naciones! Nuevo Walker sin bríos belicosos // ¿Qué pides a nuestras muchedumbres? // ¿Quieres acaso probar la linfa de estos ríos? // ó quieres ver de cerca las hondas podredumbres // que llevarán exánimes á nuestras muchedumbres // á la NOBLE palestra de vuestros desafíos ${ }^{63}$.

La ofensiva de La Información terminaba con la noticia de que en la visita de Knox iba a contar con la protección de un famoso detective que había acompañado al presidente Taft a Panamá, dados "los alarmantes rumores que han circulado por el mundo entero de posibles atentados personales contra aquel ilustre estadista norteamericano"64.

Otro componente en el discurso antiimperialista frente a la visita de Knox fue su carácter latinoamericanista y centroamericanista. Esta línea operaba como un rescate de la cultura latinoamericana y en oposición a la cultura anglosajona, que fue propia del antiimperialismo de esos años. Por ejemplo, en la edición del $1^{\circ}$ de marzo día

60 La Diplomacia del Dollar y el desembarco americano en Honduras. La Información, 29-II-1912, n $1274,1$.

${ }_{61}$ Los festejos que en Nicaragua preparan a Knox. La Información, 29-II-1912, n $1274,1$.

62 Díaz Arias, 2006: 4-5.

63 Zeledón Brenes, José María, Welcome! A Knox. La Información, 29-II-1912, n 1274, 2.

${ }_{64}$ Resguardando las espaldas al Secretario Mr. Knox. La Información, 29-II-1912, n $1274,6$. 
de la llegada de Knox, La Información vuelve a elaborar un discurso indirecto de crítica en relación con la visita y publica un extenso artículo de Salvador Corleto, un importante político hondureño, quien llegó a ser dirigente del partido Unionista Centroamericano, en este se establecía la importancia que para la independencia de los Estados Unidos tuvo Centroamérica. El artículo concluía con una manifestación en que exigía respeto por la integridad de la "Nación" centroamericana y respeto, más que agradecimiento, por parte de los Estados Unidos, en una clara referencia al expansionismo de los últimos años ${ }^{65}$.

Con una visión latinoamericanista y crítica de la postura del gobierno costarricense, el semanario La Hoja Obrera, que se identificaba como el órgano de la Sociedad de Trabajadores de Costa Rica, emitió dos pequeños artículos, el primero titulado "Knox en nuestras tierras. Algunas consideraciones importantes", en el que se establecía una comparación entre los Estados Unidos y América Latina, lo que permitía argumentar la grandeza latinoamericana frente a la potencia anglosajona. El artículo en cuestión finalizaba con una crítica a la actitud complaciente con la gira de Knox al concluir que: "[n]o seamos parias, no seamos serviles, no seamos cobardes, no representemos el mísero papel de lamer la mano de quien siempre nos ha despreciado en sus ansias de conquista; no imitemos, en fin, al esclavo de la Roma antigua" y el llamado a la solidaridad con aquellos países que había sufrido las imposiciones estadounidenses ${ }^{66}$. En la misma línea una pequeña carta dirigida a este medio se protestaba por el tratamiento que se le prodigó al secretario Knox, a quien se calificaba como "el conculcador de la libertad centroamericana" y se consideraba la visita como "un insulto á Costa Rica y la humillación más grande de nuestro decoro y como un atentado nuestra integridad nacional" $[\mathrm{sic}]^{67}$.

El segundo componente de los discursos analizados fue la valoración que se hace en distintos momentos del comportamiento de la población -especialmente los josefinos- de la visita de Knox. Sobre este punto se manejaron tres versiones. Los redactores más críticos de la visita atribuyeron la frialdad en el trato de los costarricenses para con Knox como un "castigo" a la política exterior estadounidense. Así, en el periódico La Época del 29 de febrero aparecieron las posturas sobre la actitud de los costarricenses en un pequeño artículo que calificaba la peligrosidad de los Estados Unidos y daba a entender la inquietud que experimentaba la sociedad costarricense con la llegada de Knox para lo cual establecía diferencias con el recibimiento hecho a una delación especial de El Salvador que había llegado meses atrás al país, así se indicaba que en referencia a los preparativos del recibimiento a Knox que estos eran "pura diplomacia [...] en aquel verdadera expansión, verdadero cariño, todo lo que se hacía era aprobado unánimemente por el común sentir de los costarricenses"68. Este diario mantuvo su tono crítico, cuando al efectuar el 3 de marzo un resumen de la visita señaló que al llegar a Puerto Limón Knox incluyó en su discurso la frase "yo espero algún día hacer mi hogar en esta República", lo que consideró como una afirmación que podía tener una interpretación amarga ${ }^{69}$.

65 Corleto, Salvador, La cooperación de Centro América a la independencia de los Estados Unidos. La Información, 29-II-1912, $\mathrm{n}^{\circ} 1275,2$.

${ }_{66}$ Casal, Miguel, Knox en nuestras tierras. Algunas consideraciones importantes. La Hoja Obrera, 5-III-1912, ${ }^{\circ}$ 96,3 .

67 Meza, José, Mi protesta. La Hoja Obrera, 5-III-1912, n 96, 3.

68 La llegada de Mr. Knox. La Época. Diario Católico Independiente, 29-II-1912, n $248,2$.

69 El Ministro Knox entre nosotros. La Época. Diario Católico Independiente, 3-III-1912, n 251, 2. 
Siguió esta misma línea el redactor de La Información, en este diario, pese a concluir que "la llegada de Knox ha sido para San José un acontecimiento que ha hecho época"70, en la edición del 3 de marzo dedica algunos párrafos a comentar la frialdad del pueblo en los actos públicos de la visita oficial, lo cual el redactor calificó como una protesta contra la política imperialista de los Estados Unidos, para lo cual uso como ejemplo el concierto del 2 de marzo cuando al tocarse el himno estadounidense: "la concurrencia oyó sin chistar ni aplaudir; luego se tocó el de Costa Rica; hubo nutridos y prolongados aplausos y vivas para la República"71.

Posteriormente, La Información, esta vez en una nota editorial, enfocó con mayor claridad el argumento, por lo que retomó la calidez existente durante la visita diplomática salvadoreña como punto de comparación de la frialdad con que fue recibido Knox. En este sentido, al señalar que "habrá encontrado muy justo ese silencioso reproche de un pueblo que sin salir de los términos de más pulcra corrección, reprueba los avances del imperialismo y los peligrosos enredos de la diplomacia del dollar [sic]" ${ }^{\prime 2}$, el editorialista afirmaba la excepcionalidad costarricense al tiempo que calificaba críticamente las posturas estadounidenses.

La segunda línea, sostenida por periódico El Republicano, consistía en describir la actitud silenciosa de los costarricense, pero sin profundizar en los hechos o interpretarlos. Así, al producirse el arribo de Knox a San José describía como el "gentío era si no muy numeroso, bastante crecido", además, describió que en los espectadores se notaba "más la curiosidad que el entusiasmo de recibir al honorable huésped"73. De igual forma, puntualizó que tras los saludos de rigor y al entonarse el himno de los Estados Unidos se guardó indiferencia y un "silencio mustio", mientras que el himno costarricense "animó con sus alegres notas los corazones decaídos"74.

La tercera versión, que se encuentra en El Noticiero, no hacía referencia al silencio de los josefinos y obviaba descripciones detalladas. Por el contrario, al narrar en un artículo dedicado a los dos primeros días de Knox en Costa Rica, el redactor sostuvo que "motivo de legítima satisfacción para el pueblo costarricense espontánea como brillante que se le ha hecho al señor Philander Knox", más adelante dejaba claro que esta había sido general y no daba pie a pensar en la existencia de molestia alguna con la presencia del secretario de Estado en el país, pues "[n]ingún elemento social, ninguna de las entidades trabajadoras han dejado de apresurarse á dar la bienvenida al distinguido huésped"75.

Desde la disputa discursiva descrita resultaba fundamental mostrar la postura de la población sobre la política estadounidense y su representante, pues ello contribuía a retroalimentar cada uno de los discursos en juego. Empero, se mantuvo concordancia en la prensa que durante el transcurso de la visita no se produjeron incidentes o protestas directas por parte de la población hacia Knox y su comitiva. Este elemento, como se planteará más adelante, vendría a establecer diferencias significativas con los escenarios que se producirían en otros destinos de la gira.

\footnotetext{
Mr. Knox en San José. Recibimiento que se le ha hecho al ilustre visitante. La Información, 2-III-1912, n $1275,2$. Mr. Knox en San José. La Información, 3 de marzo de 1912, n 1276, 3.

La Información, 3-III-1912, $\mathrm{n}^{\circ} 1276,2$.

La llegada del señor Knox. Su recibimiento. El Republicano, 2-III-1912, n 42, 3.

Mr. Knox en San José. Recibimiento que se le ha hecho al ilustre visitante. La Información, 2-II-1912, n 1275 , 2; La llegada del señor Knox. Su recibimiento. El Republicano, 2-III-1912, n 42, 3.

75 Mr. Knox es grandemente agasajado. El Noticiero, 3-III-1912, n 2912, 2.
} 
Tras la salida de Knox, según sus posicionamientos, los periódicos costarricenses esbozaron sus conclusiones que venían a reforzar las impresiones iniciales sobre el paso del diplomático por el país. En esta línea, El Republicano se felicitaba por los resultados de la visita, dado que Knox se había llevado las mejores impresiones del país, pues este había demostrado que, a pesar de la pequeñez, "sus hijos son grandes y dignos, demostrando llevar en sus venas toda la hidalguía de la nobleza castellana y de la raza íbera". Destacaba, igualmente, "la cordura de nuestro pueblo", con lo que reforzaba la idea de la excepcionalidad costarricense, que constituía el motivo por el cual al "Pueblo de Costa Rica se le prepara un hermoso horizonte de luz, un bello porvenir de civilización, de riqueza, de gloria" ${ }^{\text {"76 }}$.

Asimismo, un colaborador no identificado del mismo periódico aceptaba la existencia en Costa Rica de posiciones contrarias a la presencia de Knox en el país, emitidas por costarricenses y exiliados nicaragüenses, sin embargo, celebraba la diferencia costarricense respecto de sus vecinos de permitir la libre circulación de ideas que -según el autor- no debía extrañarle a Knox, pues resultaba muy similar al existente en los Estados Unidos, por ello, “[c]uando el americano notable que acaba de irse llegue á su tierra, podrá decir que fué este el único sitio libre en la América Central"'77.

Por otra parte, La Época siguió con su discurso crítico antiimperialista pero esta vez en un tono jocoso, así emitió un resumen semanal, titulado "Los asuntos de actualidad, Mr. Knox y los temblores. Terribles coincidencias". En este establecía una relación entre la recién pasada visita y los temblores que sacudieron al país días antes de esta. De tal forma, el redactor -con sorna inevitable-señaló: "tal parece que nuestro suelo hondamente se resiente ante las pisadas del gran Agente de Washington y el imperialismo yankee". Asimismo, valoró la actuación del gobierno como la única posible y estableció que "el pueblo contempló impasible, y ahogando en su corazón amargos resentimientos al gran Magnate". Por último, al comparar los casos de otros países y la intervención estadounidense (Nicaragua y Chile), el redactor llama a la defensa de la patria y retoma el argumento de la excepcionalidad costarricense al señalar "y si el caso llega [algún tipo de intervención] demostremos a los yankees que este no es un pueblo de degenerados sino de patriotas"78.

A partir de la evidencia estudiada en este acápite puede concluirse la existencia de una división de posturas existente en Costa Rica respecto de los Estados Unidos y su política exterior. En esta línea, si bien los discursos menos críticos aceptaban la existencia de las tesis imperialistas de los gobiernos estadounidenses, lo cierto es que argumentativamente manejaban esa realidad apelando a la diferencia costarricense, dado que en virtud de su existencia se había conseguido evitar ese tipo de intervenciones y, por ende, se exhortaba a manejar con prudencia la relación con la potencia hegemónica. En otros términos, el tener instituciones democráticas y progreso social constituía la mejor defensa contra el despliegue estadounidense en el istmo. Esta visión pragmática de la realidad política regional (fomentada como se ha descrito por el gobierno y una gran parte de las elites políticas y económicas), se enfrentaba con otra visión antiimperialista, que sentía un fuerte temor y desprecio por las ambicio-

\footnotetext{
La despedida de Mr. Knox y su acompañamiento. El Republicano, 5-III-1912, n 43, 2.

Ibídem.

78 Los asuntos de actualidad, Mr. Knox y los temblores. Terribles coincidencias. La Época. Diario Católico Independiente, 5-III-1912, $\mathrm{n}^{\circ} 252,2$.
} 
nes estadounidenses. No obstante, las posturas críticas y antiimperialistas tampoco eran unívocas, dado que han podido detectarse que no todas sus expresiones valoraban igual la actuación del gobierno y las posturas que debían tenerse ante la visita como pudo observarse en este acápite.

\section{Impresiones imperiales}

Además de las luchas dialécticas en la prensa nacional, resulta relevante cuestionarse sobre los efectos que la visita causó en las autoridades estadounidenses. A lo largo de la segunda mitad del siglo XIX, las autoridades estadounidenses habían empezado a establecer una imagen de la sociedad costarricense, según han estudiado Soto-Quirós y Gólcher la idea de una población "blanca", "pacífica" y "laboriosa" fue diseminada tanto por viajeros anglosajones como por el propio gobierno costarricense. De acuerdo con los trabajos de ambos autores, esta idea se torna recurrente en a partir de artículos periodísticos, panfletos de inmigración, libros publicados en el exterior y la participación en ferias y exposiciones internacionales ${ }^{79}$.

Indudablemente, los diplomáticos estadounidenses habían estado expuestos a esta información, por lo que resulta de interés establecer como fue valorada la visita oficial por el propio Knox y el jefe de la misión diplomática estadounidense en San José y, de esta forma, determinar cómo se construyen percepciones recíprocas que afecten las decisiones de política exterior que se tomaron posteriormente. Lamentablemente, a esos efectos no fueron encontrados para esta investigación una suma categórica de evidencia, no obstante, los discursos de Knox, los informes de la legación estadounidense en San José y los informes de la legación costarricense en Washington permiten un acercamiento inicial a este problema.

Durante su visita Knox brindó tres mensajes oficiales, de los cuales el más relevante fue la respuesta al mensaje que el presidente Jiménez efectuó durante el banquete del 3 de marzo. En esa ocasión Knox retomó la idea de la similitud de las instituciones políticas, destacó la cercanía del comercio costarricense con la economía estadounidense, así como la intensidad de la amistad entre el pueblo costarricense y el estadounidense ${ }^{80}$. El secretario de Estado señaló que:

Es con una sensación de expectativa cumplida que uno encuentra a cada paso las expresiones del tradicional amor de su pueblo por la educación, no solo en sus formas pragmáticas, sino también en las bellas artes, la arquitectura notable y la música, y también puede verse en las caras felices y radiantes de los niños el reflejo de la belleza de sus madres y cualidades robustas de sus padres ${ }^{81}$.

Más adelante, Knox haría referencia al carácter pacífico del pueblo costarricense, con tal fin, ligaba tal actitud con la participación costarricense en los tratados de Washington de Costa Rica, la instauración de la Corte de Justicia Centroamericana

79 Soto-Quirós, 2012 y 2013; Gólcher, 1998.

80 Discurso del secretario de Estado, Philander Knox, en Costa Rica. 3-III-1912. Reproducido en M.M. Langhorne, nota dirigida al subsecretario de Estado H. Wilson, 7-III-1912. File n ${ }^{\circ} 033.1100$ K77/91. U.S. Department of State, 1919. Disponible en http://digital.library.wisc.edu/1711.dl/FRUS.FRUS1912

81 Ibídem. Traducción libre del autor. 
en Cartago y la decisión de someter las diferencias fronterizas con Panamá mediante un proceso arbitral ante el presidente de la Corte Suprema de los Estados Unidos, en tal sentido, concluía que:

La actitud de la República de Costa Rica también ha sido constante y se evidencia ampliamente en el curso adoptado para el arreglo de la disputa limítrofe centenaria con Panamá. Repito, señor Presidente [sic], que el pueblo de Costa Rica debe felicitarse a sí mismo de que en su seno se encuentra el hogar de la Corte Centroamericana de Justicia, el único tribunal ante el cual una nación puede traer otra-sí, ante la cual un individuo puede llevar a una nación a determinar ante un tribunal de justicia imparcial las diferencias que existen entre ellos ${ }^{82}$.

Por último, Knox tomaba partes del discurso identitario costarricense, al señalar que la prosperidad experimentada por el país eran frutos del amor a la paz, la libertad y justicia, asimismo, brevemente recapitulaba el mito de la nación igualitaria de "pequeños terratenientes" para establecer la posición excepcional de Costa Rica en el continente y la cercanía entre el pueblo estadounidense y el costarricense. Así concluía que:

Permítame expresar el sentimiento de profunda satisfacción que el pueblo y el Gobierno de los Estados Unidos albergan, no solo por la creciente prosperidad de Costa Rica, sino también por su amor a la paz, por el respeto que inspira en la familia de las naciones, porque ella ha puesto los cimientos de la libertad perpetua sobre la roca eterna de la justicia y por ello ocupa una posición excepcional y envidiable entre las repúblicas americanas; así como por la distribución general de la propiedad entre su pueblo y a la intimidad y amistad constantemente entre su gente y la nuestra ${ }^{83}$.

¿Cuán diplomáticas fueron estas afirmaciones? De una lectura de los discursos emitidos por Knox en Guatemala y Nicaragua puede colegirse una serie de diferencias que evidencian percepciones distintas sobre el pasado y las condiciones políticas que experimentaban estos en comparación con la que experimentaba la sociedad costarricense de la época. De tal manera, en su banquete de honor en Nicaragua, Knox planteaba la necesidad de los Estados Unidos de "colaborar" en la prosperidad y "regeneración" de Nicaragua, la cual -de forma diplomática- reproducía los pilares que orientaban la "Diplomacia del Dólar" a los que se hizo referencia en segundo acápite de este trabajo. Por consiguiente, al explicar la intervención estadounidense en Nicaragua puntualizaba que:

La situación política y económica que surgió, debido a muchos años de mal gobierno, transformó la tarea de reorganización de su Estado en una extremadamente difícil, y sus líderes, debido a la franca amistad y buena fe de los Estados Unidos hacia el pueblo nicaragüense, naturalmente recurrieron al gobierno estadouniden-

Ibídem. Traducción libre del autor.

Ibídem. Traducción libre del autor. 
se para brindar el consejo y la asistencia en la ardua tarea que tienen ante sí. Mi Gobierno se alegró de enviar a Managua un comisionado especial para ayudar a hacer un programa final que los líderes se comprometieron a llevar a cabo y en el que se contemplaba la cooperación en la rehabilitación de Nicaragua ${ }^{84}$.

Por otra parte, en un discurso que correspondía al pronunciado por el presidente guatemalteco Manuel Estrada Cabrera (1898-1920), Knox establecía como problema central de la mayor parte de los países centroamericanos sus enfrentamientos políticos internos y los reiterados conflictos que experimentaban los centroamericanos entre sí, por lo que puntualizaba que:

En América Central, Estados Unidos tiene un interés especial no solo por la proximidad de las cinco repúblicas a la gran ruta comercial que está por concluirse en Panamá, sino también por sus obligaciones morales establecidas en las convenciones de Washington. El mantenimiento de la paz y las condiciones de estabilidad en estas repúblicas es una cuestión de primera importancia para mi Gobierno. La fiel observancia de estas convenciones, en opinión de mi Gobierno, conducirá a la eliminación de la agitación que hasta ahora ha sacudido los cimientos de algunos de los menos afortunados e intranquilos países ${ }^{85}$.

En síntesis, mientras que el pasado costarricense se percibía como la base para un porvenir de progreso y amistad entre ambos países; el pasado para los casos de Nicaragua y Guatemala debía ser corregido. Esta transformación de los acontecimientos del pasado provenía de la colaboración de los Estados Unidos, tanto de forma bilateral como regional. Resulta claro, al menos en caso de Knox, que el desarrollo costarricense representaba una excepción respecto de las visiones generales que este mantenía de Centroamérica.

Estas apreciaciones públicas se unían a algunas que circulaban en los medios nacionales. Por ejemplo, La Información en la edición del 5 de marzo, reproducía los comentarios de un intérprete que aprovechó un momento en el tren que trasladaba a la comitiva estadounidense de San José a Puntarenas para consultarle Knox cuáles impresiones le dejaba Costa Rica, el secretario respondió que:

Muy buenas, díjome, admiro este país por la grandeza de su naturaleza, por la bondad y la laboriosidad de sus hijos, la belleza de sus mujeres, por sus instituciones políticas; esto, agregó, sin miramientos diplomáticos de ninguna naturaleza; y siguió: conocía á Costa Rica por periódicos y libros; me habían elogiado mucho las bondades de este país; francamente las suponía exageradas, pero ahora voy convencido de que periodistas y escritores tienen suficiente razón y sobrados motivos para elogiar a esta pequeña República, que tan grandes tesoros guarda en su seno ${ }^{86}$.

84 Discurso del secretario de Estado, Philander Knox. Nicaragua, 6-III-1912. U.S. Department of State, $1913: 39$. Traducción libre del autor.

85 Discurso del secretario de Estado, Philander Knox. Guatemala, 16-III-1912. U.S. Department of State, 1913: 124. Traducción libre del autor.

86 Agasajos a Mr. Knox. El banquete y el baile. Despedida a los ilustres huéspedes. La Información, 5-III-1912, ${ }^{\circ}$ 1278, 4. 
En mayo de 1912, el ministro costarricense en Washington tuvo una reunión con Knox, en esta el secretario de Estado volvió a asegurar que la visita había superado sus expectativas, además, señaló las diferencias que encontró entre Costa Rica y los otros países que visitó en su gira. El ministro aseguró en el informe remitido a la Secretaria de Relaciones Exteriores que las expresiones de Knox habían sido repetidas entre otras reuniones y otros funcionarios estadounidenses con que se había tenido contacto. A juicio del diplomático costarricense Knox había quedado realmente sorprendido con lo visto en el Costa Rica y esto contribuiría al buen estado de las relaciones entre ambos gobiernos ${ }^{87}$.

Más allá de los cuestionamientos a la existencia de formas diplomáticas en el discurso y la reunión de cortesía; así como la veracidad de esta anécdota, lo cierto es que ambos concordaban con los informes internos que elaboró el encargado de negocios estadounidense en San José, Marshall M. Langhorne, tanto de previo como posterioridad a la visita. Tres días antes del arribo de Knox a Limón, Langhone informaba que el gobierno había preparado con todo detalle una agenda para recibir al secretario Knox y que todo se encontraba bien dispuesto para su llegada, incluso señalaba que el hospedaje de Knox sería de muy buen nivel y que tendría todo dispuesto para su estadía ${ }^{88}$. Luego de la partida de la delegación estadounidense el encargado de negocios consideraba que la visita había sido tal y cual se había programado con anticipación. Además, daba especial relevancia a que Knox había sido recibido con cordialidad y hospitalidad, asimismo, que había fue sujeto de múltiples expresiones "de la mayor buena voluntad". Lo anterior, llevó al diplomático estadounidense a calificar el paso de Knox por Costa Rica como "un gran éxito" que permitiría fortalecer las relaciones entre ambos países ${ }^{89}$.

El informe demuestra como para el caso concreto de las autoridades estadounidenses protagonistas de la visita esta funcionó como una comprobación de la "excepcionalidad" costarricense en istmo, así como la cercanía de las autoridades del país centroamericano con los Estados Unidos. Posiblemente, los incidentes violentos que se produjeron en Nicaragua durante la visita de $\mathrm{Knox}^{90}$, como protesta a las intervenciones estadounidenses cada vez más evidentes en este, pudieron fomentar aún la imagen de la laboriosa y pacífica Costa Rica.

\section{A modo de conclusión}

La visita de Philander Chase Knox constituye una muestra expresiva de las características de la relación entre Costa Rica y los Estados Unidos. La evidencia recolectada para la elaboración de este texto permite acercarse a las impresiones que las autoridades estadounidenses tenían de Costa Rica en las primeras décadas del siglo XX, está imagen, a la luz del material estudiado, tenía componentes muy positivos en torno a la noción de una sociedad "avanzada y civilizada"; sin embargo, son ne-

87 Carta J.B. Calvo, ministro de Costa Rica en Washington a Manuel Castro Quesada, secretario de Relaciones Exteriores de Costa Rica. 5-III-1912. ANCR, RREE.21917.

88 M.M. Langhorne, nota dirigida al subsecretario de Estado H. Wilson, 26-II-1912. File n ${ }^{\circ} 033.1100$ K77/51. U.S. Department of State, 1919. Disponible en http://digital.library.wisc.edu/1711.dl/FRUS.FRUS1912

89 M.M. Langhorne, nota dirigida al subsecretario de Estado H. Wilson. 7-III-1912. File no 033.1100 K77/91. U.S. Department of State, 1919. Disponible en http://digital.library.wisc.edu/1711.dl/FRUS.FRUS1912

90 Gobat, 2005: 82. 
cesarias investigaciones posteriores para determinar la evolución y los mecanismos mediante los cuales estas percepciones se fueron reproduciendo en la diplomacia estadounidense.

Desarrollada por la elite costarricense, esta imagen era reproducida sistemáticamente en su política exterior, por lo que la presencia de Knox constituía un momento oportuno y relevante para seguir esa línea. De tal manera, el gobierno costarricense siguió un guion pragmático de lo que debían ser las relaciones con los Estados Unidos, a pesar de las preferencias políticas de algunas de sus figuras (entre ellas el presidente y el subsecretario de Relaciones Exteriores), las dudas sobre la presencia estadounidense en el país y la presión que se desarrolló en parte de la prensa antiimperialista de la época.

En los años siguientes, Costa Rica tendría que enfrentar una oleada más intensa de intervenciones estadounidenses en la región, las que afectarían directamente sus derechos territoriales. Asimismo, la dictadura de los Tinoco (1917-1919), al tomar decisiones que afectaron a intereses económicos de los Estados Unidos en el país, provocó la ruptura temporal de relaciones diplomáticas y casi produjo una intervención militar. Sin embargo, la tensión no sería suficiente para romper las percepciones previamente creadas, por el contrario, estas parecen haberse robustecido con el establecimiento de la política estadounidense del "buen vecino" en la década de 1930.

Por otra parte, la visita de Knox permite apreciar como las percepciones de la población costarricense hacia los Estados Unidos no siempre fueron tan cordiales como en la segunda mitad del siglo XX. Sin posibilidades de precisar el peso de las ideas antiimperialistas dentro de la población costarricense, lo cierto es que estas circulaban dinámicamente entre esta y tenían algún grado de influencia en su comportamiento, sin que este pudiera condicionar en este caso concreto la actuación de las elites políticas que en ese momento manejaban las relaciones exteriores. Habría que esperar a la propaganda de la Segunda Guerra Mundial y los primeros años de la Guerra Fría para que a partir de los combates ideológicos que se produjeron dentro de dichas contiendas las apreciaciones terminaran por transformar las visiones de la sociedad costarricense mayoritariamente a favor de los Estados Unidos y su política exterior.

\section{Referencias bibliográficas}

Acuña Ortega, Víctor Hugo. "La invención de la diferencia costarricense 1810-1870". Revista de Historia, $\mathrm{n}^{\circ} 45$ (2002), 191-228.

Cascante Segura, Carlos Humberto. La política exterior de Costa Rica (1850-2010). San José: Editorial UCR, 2015.

Coastworth, John. Central America and the United States: The Colossus and the Clients. Nueva York: Twayne Publichers, 1994.

Cuevas Molina, Rafael. Sandino y la intelectualidad costarricense: nacionalismo antiimperialista en Nicaragua y Costa Rica (1927-1934). San José: Editorial Universidad Estatal a Distancia, 2008.

Díaz Arias, David. Historia del 11 de abril: Juan Santamaría entre el pasado y el presente (1915-2006). San José: Editorial UCR, 2006.

- “A los pies del águila: la visita de John F. Kennedy a Costa Rica en 1963”. En El verdadero anticomunismo. Política, género y Guerra Fría en Costa Rica (1948-1973), editado por 
Molina, Iván - Díaz Arias, David. San José: Editorial Universidad Estatal a Distancia, 2017, 179-214.

Dinwoodie, D. H. "Dollar Diplomacy in the Light of the Guatemalan Loan Project, 19091913". The Americas, no 26, vol. 3 (1970), 237-253.

Dodd, Thomas. "La Corte de Justicia centroamericana, 1907-1908: su legado, la defensa de derechos individuales". Revista de Historia, no 12-13 (1986), 67-82. Disponible en http:// www.revistas.una.ac.cr/index.php/historia/article/view/3190/3049

Editorial Comment, "Secretary Knox's Visit to Central America", The American Journal of International Law, vol. 6, $\mathrm{n}^{\circ} 2$ (1912), 493-498.

Fumero Vargas, Patricia. El advenimiento de la modernidad en Costa Rica. San José: Editorial UCR, 2005.

Gobat, Michel. Confronting the American Dream. Nicaragua under U.S. Imperial Rule. Durhan - London: Duke University Press, 2005.

Gobierno de la República de Costa Rica. Memoria anual de labores, 1912.

Gólcher Barguil, Érica, "Imperios y ferias mundiales: la época liberal”, Anuario de Estudios Centroamericanos, $\mathrm{n}^{\circ}$ 2, vol. 24 (1998), 75-94.

Grandin, Greg. The Empires's Workshop. Latin America, the United States, and the Rise of New Imperialism. Nueva York: Metropolitan Books, 2006.

Herring, George. The American Century and Beyond. US Foreign Relations 1893-2014. Nueva York: Oxford University Press [Kindle Edition], 2008.

Inacua Gómez, Sandra. Del anticolonialismo al antiimperialismo: gestación de un movimiento en resistencia. Pacarina del Sur, no 26, año 7, (2016). Disponible en http://pacarinadelsur. com/home/abordajes-y-contiendas/1261-del-anticolonialismo-al-antiimperialismogestacion-de-un-movimiento-en-resistencia

Legación de Costa Rica en Washington D.C., The Visit to Costa Rica of His Excellency The Secretary of State of the United States of America, 1912.

Lindo-Fuentes, Héctor. "Respuestas subalternas a los designios imperiales. Reacción salvadoreña a la primera intervención de Estados Unidos en Nicaragua". Anuario de Estudios Centroamericanos, ${ }^{\circ} 41$ (2015), 29-65.

Longley, Kyle. The Sparrow and the Hawk. Costa Rica and United States during the rise of Jose Figueres. Alabama: University of Alabama Press, 1997.

- In the Eagles's Shadow. Illinois: Harlan Davidson Inc, 2002.

Maya Sotomayor, Teresa. "Estados Unidos y el panamericanismo: el caso de la I Conferencia Internacional Americana (1889-1890)". Historia Mexicana, nº 4, vol 45 (1996), 759-781.

Mayring, Philip. Qualitative Content Analysis. Theoretical Fundation, Basis Procedures and Software Solutions. Klagenfurt, 2014.

McPherson, Alan. A Short History of of U.S. Interventions in Latin America and the Caribbean. Oxford: John Wiley \& Sons, Inc., 2016.

Merlos, Salvador Ricardo. América Latina en peligro. San José: Imprenta Matamoros, 1914.

Molina Jiménez, Iván - Palmer, Steven. Héroes al gusto y libros de moda: sociedad y cambio cultural en Costa Rica (1750-1900). San José: Editorial Porvenir y Plumsock Mesoamerican Studies, 1992.

- Historia de Costa Rica. San José: Editorial UCR, 2007.

- Ricardo Jiménez Oreamuno. San José: Editorial Euned, 2008.

Morales, Gerardo. Cultura oligárquica y nueva intelectualidad en Costa Rica: 1880-1914. Heredia: Editorial UNA, 1992.

Murillo Jiménez, Hugo. Tinoco y los Estados Unidos. Génesis y caída de un regimen. San José: Editorial Universidad Estatal a Distancia, 1981. 
O'Brien, Thomas. Making the Americas. The United States and Latin America from the Age of Revolutions to the Era of Globalization. Albuquerque: University of New Mexico Press, 2007.

Olander, Marcia. “Costa Rican in 1948: Cold War or Local War?”. The Americas, $\mathrm{n}^{\circ}$ 52, vol. 4 (1996), 465-493. Disponible en http://www.jstor.org/stable/1008474

Quesada Monge, Rodrigo. Keith en Centroamérica. Imperios y empresas en el siglo XIX. San José: Editorial UNED, 2013

Rodríguez Díaz, María del Rosario. "La misión diplomática de Elihu Root en América Latina y el Caribe, 1906". Revista Mexicana del Caribe, no 18, año 9 (2004), 129-148. Disponible en http://www.redalyc.org/articulo.oa?id=12801803

Rosemberg, Emily. Financial Missioners of the World. The Politics and Culture of Dollar Diplomacy, 1900-1930. Massachusetts: Harvard University Press, 1999.

Sáenz Carbonell, Jorge Francisco. Historia Diplomática de Costa Rica, tomo I. (1821-1910). San José: Editorial Juricentro, 1996.

- Historia Diplomática de Costa Rica, tomo II. (1910-1948). San José: Editorial Juricentro, 2000.

Salisbury, Richard. Costa Rica y el istmo 1900-1934. San José: Editorial Costa Rica, 1984.

- "La lucha antiimperialista de Alejandro Alvarado Quirós". Anuario de Estudios Centroamericanos, $\mathrm{n}^{\circ} 8$ (1982), 85-98.

Schifter Sikora, Jacobo. Las alianzas conflictivas: las relaciones de Costa Rica con los Estados Unidos de la Segunda Guerra Mundial a los inicios de la Guerra Fría. San José: Libro Libre, 1986.

Schreier, Margrit. Qualitative Content Analysis. London: Sage, 2012.

Solís Rivera, Luis Guillermo. "Costa Rica y Estados Unidos”. En Costa Rica y el sistema internacional. editado por Rojas Aravena, Francisco. San José: Editorial Nueva Sociedad, 1990, 23-48.

Soto-Quirós, Ronald. "La difusión del etnotipo costarricense: los Apuntamientos de J. B. Calvo, del texto educativo a la propaganda internacional." Boletín AFEHC, $\mathrm{n}^{\circ} 54$ (2012).

- "Whiteness studies y relatos de viajeros: los costarricenses en las miradas anglosajonas (1844-1868)". Boletín AFEHC, no 57 (2013).

U.S. Department of State. Speeches. Incident to the Visit of Philander Chase Knox, Secretary of State of the United States of America, to the Countries of the Caribbean. Washington: Government Printing Office, 1913.

- Papers relating to the foreign relations of the United States with the annual message of the president transmitted to Congress December 3, 1912. 1919. Disponible en http:// digital.library.wisc.edu/1711.dl/FRUS.FRUS1912 